\title{
Frequently Encountered Animal Diseases at Animal Hospital Birnin Kebbi, Kebbi State - Nigeria
}

\author{
*GARBA 1 , A., AHMED', A., AMBURSA², A.U., FARUK³, A, KALGO³, K. S., GARBA², G.J., \\ MAURICE ${ }^{3}$, N.A., UMAR ${ }^{5}$, T.A., SALAM ${ }^{4}$, S.P and IDRIS ${ }^{4}$, S.
}

1. Zonal Investigation Laboratory, National Veterinary Research Institute, B/Kebbi ${ }^{2}$ Livestock Investigation and Breeding Center, Bulasa$\mathrm{B} / \mathrm{Kebbi}^{3}{ }^{3 .}$ Diagnostics and Extension Division, National Veterinary Research Institute, Vom ${ }^{4}$ Animal Hospital, Min. of Agric \& N/Resources $\mathrm{B} / \mathrm{Kebbi}^{5}{ }^{5}$ Federal Dept. of Livestock, B/Kebbi, ${ }^{*}$ Corresponding author:- agarba nvri@yahoo.co.uk +2348036471758,8027418282

\section{SUMMARY}

Data from the clinical record of the Animal Hospital Birnin Kebbi was used to determine the frequency of occurrence of various diseases of animals from February 2009 to January 2010. A total of 794 cases were presented. $155(19.5 \%)$ for routine check and vaccination, while the bulk 639 (80.5\%) were presented as a result of disease conditions. Diseases diagnosed include; helminthoses $141(22 \%)$, followed by fowl pox $65(10.2 \%)$, lousiness $61(9.5 \%)$, traumatic injuries $46(7.2 \%)$, enteritis $32(5.0 \%)$, upper respiratory tract infection $29(4.5 \%)$, mite/mange $24(3.8 \%)$, septicemia $22(3.4 \%)$, bloat $19(3.0 \%)$, and abscess $17(2.7 \%)$. Other moderately occurring, disorders included dystocia \& post partum complications $14(2.2 \%)$ each, mal-directed horn/hooves $12(1.9 \%)$, tick infestation $10(1.6 \%)$, coccidiosis $9(1.4 \%)$, fracture $8(1.3 \%)$, hernia, PPR, pregnancy toxemia \& castration $7(1.1 \%)$ each. Poisoning, infectious coryza, arthritis, rumen impaction \& vaginal prolapse were $6(0.9 \%)$ each, pneumonia and mastitis $5(0.8 \%)$ each. The less occurring disorders included urinary tract infection, Gumboro disease, black leg, abortion, paraphimosis \& dog bite $4(0.6 \%)$ each. Rhinitis \& chronic respiratory diseases $3(0.5 \%)$ each, Foot and Mouth disease, New castle disease, cowdriosis, and hygroma numbering $2(0.3 \%)$ each. The least occurring disorders were Fowl typhoid, dislocation, trypanasomosis, pyometra, orf, stomatitis, grass tetany, canine distemper, atresia ani and rectal prolapse $1(0.2 \%)$ case each. Information generated can be useful to Government agencies involved in formulating policies and guidelines for prevention and control of animal diseases.

KEYWORDS:- Clinical record, Animal disease, Birnin- Kebbi, Nigeria.

\section{INTRODUCTION}

In most developing countries there is an acute shortage of protein of animal origin for human consumption. The average daily consumption per head in these countries is sub-optimal and insufficient to meet the minimum requirement for normal growth and development (Anyam, 2006). Nigeria is endowed with abundant livestock resources having over 13.5 million heads of cattle, 22.1 million sheep, 34.5 million goats and over 72.8 million poultry (RIM, 1992). Three quarter of the livestock resources are distributed in the northern part of the country. Despite this huge livestock population, the productivity of the livestock industry remains low due to multiplicity of constraints. Some of the constraints range from management, nutrition, climate, veterinary services and diseases. In a report, Nigeria has recognized and outlined over one hundred and eleven reportable diseases that affect livestock into list $A$ to $E$ in the order of prompt reporting requirement (Abdulkadir, 1989). In light of this, several animal diseases have been reported as occurring in different parts of the country by many authors (Fatihu et al., 1999 \& 2002; Ebbo et al., 2003; Salihu et al., 2005; Paul-Abiade et al., 2006; Okolocha et al., 2007; Olabode et al., 2008; Garba et al., 2009). However, there is little published report of the various animal diseases occurring in Birnin Kebbi, Kebbi State, Nigeria hence the need for this study.

\section{MATERIALS AND METHODS}

Data comprising of species of animals, sex, case history and clinical manifestations, diagnosis made and treatment given were retrieved from the clinical records of the Animal Hospital, Birnin Kebbi between February 2009 and January 2010. The data retrieved were analyzed and summarized in tables using descriptive statistics. The occurrence of different diseases 
diagnosed was calculated using percentages. The record of ambulatory services was not available thus not included in this report though some diseases especially of bovine origin are in the ambulatory unit.

\section{RESULTS}

A total of 794 animal conditions were reported to the hospital during the period under study. Of this number, 639 (80.5\%) were different disease conditions diagnosed and treated while 155 (19.5\%) were presented for routine treatment (deworming and vaccination). Of the 639 cases presented, 49 diseases were diagnosed (Table I) involving equine, 7 (1.1\%), bovine, $18(2.8 \%)$, ovine, 312 (48.8\%), caprine, 143 (22.4\%), canine, 30 (4.7\%), feline, $1(0.2 \%)$, lapine, 5 $(0.8 \%)$ and avian, $123(19.2 \%)$ species (Table II). Helminthoses were the most frequently encountered condition, 141 (22\%), followed by fowl pox, 65 (10.2\%), lousiness, 61 (9.5\%), traumatic injuries, 46 (7.2\%), enteritis, 32 (5.0\%), upper respiratory tract infection, 29 (4.5\%), mite/mange, 24 (3.8\%), septicemia, 22(3.4\%), bloat, 19 (3.0\%), and abscess, 17 (2.7\%) (Table I, Figure. I). Other moderately occurring disorders all constituting 21\% (figure 1) included dystocia \& post partum complications, 14 (2.2\%) each, mal-directed horn/hooves, 12 (1.9\%), tick infestation, 10 (1.6\%), coccidiosis, $9(1.4 \%)$, fracture, $8(1.3 \%)$. Hernia, PPR, pregnancy toxemia \& castration were, $7(1.1 \%)$ cases each, whilst poisoning, infectious coryza, arthritis, rumen impaction \& vaginal prolapsed, $6(0.9 \%)$ each, pneumonia and mastitis were, $5(0.8 \%)$ each. The less occurring disorders (constituting 5.8\%). (Table I, figure I) were urinary tract infection, Gumboro disease, black leg, abortion, paraphimosis \& dog bite, $4(0.6 \%)$ each. Rhinitis and chronic respiratory diseases, $3(0.5 \%)$ each, Foot \& mouth disease, New castle disease, cowdriosis, and hygroma, $2(0.3 \%)$ each. The least occurring disorders were fowl typhoid, dislocation, trypanasomosis, pyometra, orf, stomatitis, grass tetany, canine distemper, atresia ani and rectal prolapsed, $1(0.2 \%)$ case each; (constituting $2 \%$ ) (Table I, figure I). Out of the 639 cases reported, 347 (54.3\%) were in females while 292 (45.7\%) were in males (Table II). The average monthly cases reported were 66.2 per month.

Table 1: Monthly distribution of cases reported to Animal Hospital, Birnin Kebbi (Feb'2009-Jan'2010)

\begin{tabular}{|c|c|c|c|c|c|c|c|c|c|c|c|c|c|c|}
\hline S/no. & Condition & Jan & Feb & o Mar & Apr & May & Jun & Jul & I Aug & Sep & Oct & Nov & Dec. & Total(\%) \\
\hline 1. & Helminthosis & 2 & 1 & 30 & 16 & 23 & 23 & 1 & 9 & 4 & 0 & 3 & 5 & $141(22)$ \\
\hline 2. & Fowl pox & 2 & 9 & 42 & 2 & 0 & 0 & 1 & 3 & 4 & 0 & 2 & 0 & $65(10.2$ \\
\hline 3. & Lousiness & 0 & 3 & 19 & 6 & 6 & 8 & 9 & 3 & 3 & 1 & 1 & 2 & $61(9.5)$ \\
\hline 4. & Traumatic injuries & 2 & 3 & 7 & 5 & 7 & 8 & 6 & 3 & 1 & 0 & 2 & 2 & $46(7.2)$ \\
\hline 5. & Enteritis & 0 & 6 & 4 & 4 & 1 & 1 & 7 & 5 & 2 & 0 & 2 & 0 & $32(5)$ \\
\hline 6. & URTI & 1 & 3 & 4 & 4 & 4 & 6 & 2 & 2 & 0 & 0 & 1 & 2 & $29(4.6)$ \\
\hline 7. & Mite/Mange & 1 & 5 & 8 & 0 & 4 & 1 & 0 & 0 & 0 & 1 & 2 & 2 & $24(3.8)$ \\
\hline 8. & Septicemia & 1 & 1 & 11 & 0 & 1 & 2 & 4 & 1 & 0 & 0 & 0 & 1 & $22(3.5)$ \\
\hline 9. & Bloat & 1 & 3 & 3 & 3 & 1 & 4 & 2 & 1 & 1 & 0 & 0 & 0 & 19(3) \\
\hline $1 C$ & Abscess & 0 & 3 & 3 & 1 & 3 & 5 & 0 & 0 & 0 & 0 & 2 & 0 & $17(2.7)$ \\
\hline 11 & ModeratelyO.D & 5 & 24 & 28 & 22 & 10 & 21 & 9 & 6 & 1 & 1 & 3 & 6 & $136(21.3)$ \\
\hline 18 & Less O.D & 0 & 6 & 4 & 6 & 7 & 7 & 3 & 0 & 0 & 0 & 1 & 0 & $34(5.3)$ \\
\hline $1 ?$ & Least O.D & 1 & 1 & 2 & 0 & 0 & 0 & 5 & 0 & 0 & 0 & 1 & 0 & $10(1.6)$ \\
\hline & TOTAL & 16 & 80 & 166 & & 65 & 87 & 61 & 35 & 17 & 3 & 20 & 20 & 639 \\
\hline
\end{tabular}

Key:- \%= percentage, URTI= Upper respiratory tract infection, O.D= Occurring disorders,

Moderately O.D = dystocia, post partum complications, mal-directed horn/hoof, tick infestation, coccidiosis, fracture, hernia, PPR, pregnancy toxemia castration, poisoning, infectious coryza, arthritis, rumen impaction, vaginal prolapsed, pneumonia and mastitis.

Less O.D = Urinary tract infection, Gumboro, Black leg, abortion, paraphimosis, dog bite, rhinitis, chronic respiratory diseases, Foot \& mouth disease, New castle disease, cowdriosis, and hygroma.

Least O.D = Fowl typhoid, dislocation, trypanasomosis, pyometra, orf, stomatitis, grass tetany, canine distemper, atresia ani and rectal prolapsed. 
Garba et al: Common livestock Diseases in Birnin Kebbi,

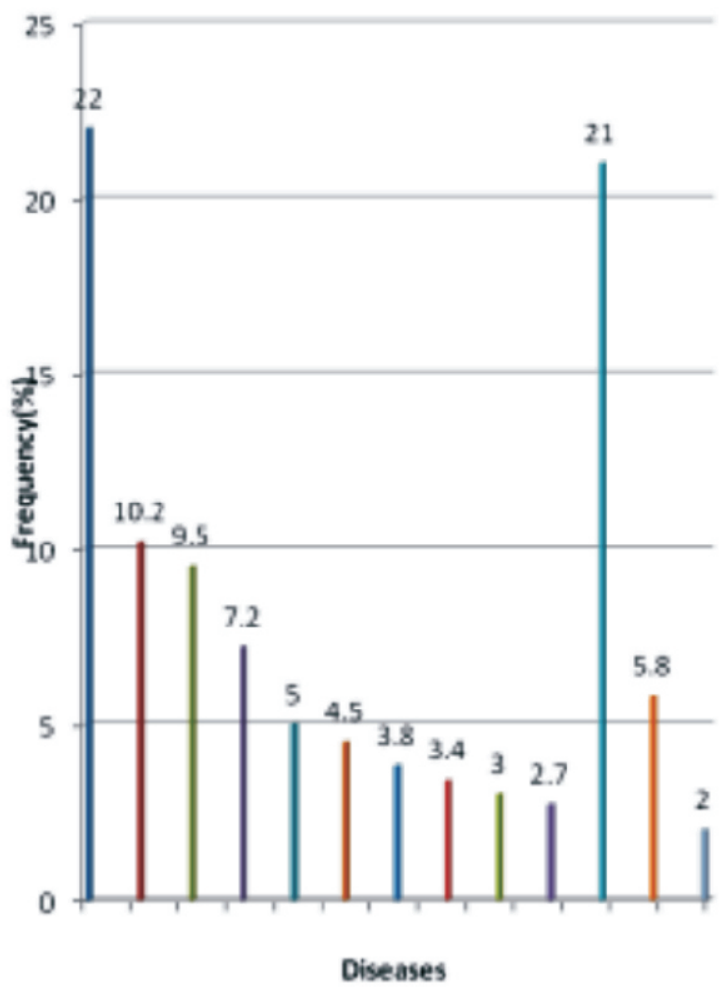

Key: Moderately O.D = dystocia, post partum complications, maldirected horn/hoof, tick infestation, coccidiosis, fracture, hernia, PPR, pregnancy toxemia castration, poisoning, infectious coryza, arthritis, rumen impaction, vaginal prolapsed, pneumonia and mastitis.

Less O.D = Urinary tract infection, Gumboro, Black leg, abortion, paraphimosis, dog bite, rhinitis, chronic respiratory diseases, Foot \& mouth disease, New castle disease, cowdriosis, and hygroma.

Least O.D = Fowl typhoid, dislocation, trypanasomosis, pyometra, orf, stomatitis, grass tetany, canine distemper, atresia ani and rectal prolapsed.

Figure 1: Frequency of distribution of animal diseases in Birnin Kebbi (Feb. '2009 - Jan. 2010)

Table II: Species and sex distribution of animal cases reported at the Animal Hospital Birnin Kebbi (Feb '2009- Jan '2010)

\begin{tabular}{llllllllll}
\hline Condition & EQ & Bov & Ov & Cap & $\begin{array}{l}\text { Can } \\
\text { M/F }\end{array}$ & $\begin{array}{l}\text { Fel } \\
\text { M/F }\end{array}$ & $\begin{array}{l}\text { Lap } \\
\text { M/F }\end{array}$ & $\begin{array}{l}\text { Av } \\
\text { M/F }\end{array}$ & Total \\
\hline Helminthosis & $0 / 0$ & $2 / 0$ & $32 / 51$ & $8 / 24$ & $9 / 2$ & $0 / 0$ & $0 / 0$ & $6 / 7$ & $\mathbf{5 7 / 8 4}$ \\
Fowl pox & $0 / 0$ & $0 / 0$ & $0 / 0$ & $0 / 0$ & $0 / 0$ & $0 / 0$ & $0 / 0$ & $35 / 30$ & $35 / 30$ \\
Lousiness & $0 / 0$ & $2 / 0$ & $18 / 19$ & $3 / 7$ & $3 / 0$ & $0 / 0$ & $0 / 0$ & $4 / 5$ & $\mathbf{3 0 / 3 1}$ \\
Traumatic iniuries & $4 / 0$ & $0 / 0$ & $7 / 11$ & $5 / 6$ & $4 / 0$ & $0 / 0$ & $0 / 0$ & $3 / 6$ & $\mathbf{2 3 / 2 3}$ \\
Enteritis & $0 / 0$ & $0 / 0$ & $13 / 10$ & $5 / 1$ & $1 / 0$ & $0 / 0$ & $0 / 0$ & $0 / 2$ & $\mathbf{1 9 / 1 3}$ \\
URTI & $0 / 0$ & $2 / 0$ & $6 / 8$ & $6 / 4$ & $0 / 0$ & $0 / 0$ & $0 / 0$ & $3 / 0$ & $\mathbf{1 7 / 1 2}$ \\
Mite/Mange & $1 / 0$ & $0 / 1$ & $4 / 6$ & $1 / 2$ & $2 / 0$ & $0 / 0$ & $4 / 1$ & $1 / 1$ & $\mathbf{1 3 / 1 1}$ \\
Septicemia & $0 / 0$ & $0 / 0$ & $10 / 8$ & $1 / 3$ & $0 / 0$ & $0 / 0$ & $0 / 0$ & $0 / 0$ & $\mathbf{1 1 / 1 1}$ \\
Bloat & $0 / 0$ & $0 / 0$ & $6 / 4$ & $1 / 8$ & $0 / 0$ & $0 / 0$ & $0 / 0$ & $0 / 0$ & $\mathbf{7 / 1 2}$ \\
Abscess & $1 / 0$ & $0 / 1$ & $4 / 7$ & $2 / 2$ & $0 / 0$ & $0 / 0$ & $0 / 0$ & $0 / 0$ & $\mathbf{7 / 1 0}$ \\
Moderately O.D & $0 / 0$ & $2 / 3$ & $17 / 56$ & $10 / 30$ & $6 / 0$ & $0 / 1$ & $0 / 0$ & $2 / 2$ & $\mathbf{3 7 / 9 2}$ \\
Less O.D & $0 / 0$ & $4 / 2$ & $11 / 2$ & $4 / 4$ & $1 / 1$ & $0 / 0$ & $0 / 0$ & $2 / 0$ & $\mathbf{2 7 / 9}$ \\
Least O.D & $1 / 0$ & $1 / 1$ & $1 / 1$ & $2 / 1$ & $1 / 0$ & $0 / 0$ & $0 / 0$ & $3 / 1$ & $\mathbf{9 / 4}$ \\
Total & $7 / 0$ & $12 / 6$ & $130 / 182$ & $48 / 95$ & $27 / 3$ & $0 / 1$ & $4 / 1$ & $64 / 59$ & $\mathbf{2 9 2 / 3 4 7}$ \\
& $7(1.1)$ & $18(2.8)$ & $312(48.8)$ & $143(22.4)$ & $30(4.7)$ & $1(0.2)$ & $5(0.8)$ & $123(19.2)$ & $\mathbf{6 3 9}(\mathbf{1 0 0})$ \\
\hline
\end{tabular}

Key:- \%= percentage, URTI= Upper respiratory tract infection, O. D= Occurring disorders,

\section{DISCUSSION}

The promulgation of veterinary legislations in Nigeria dates back to October, 1917 when the Diseases of Animals Ordinance ( now known as Animal Diseases (Control) Decree 10, 1988) was enacted with the aim of backing the veterinary efforts in preventing and controlling of animal disease outbreaks in the country (Olukole, 2008). Of the 639 presented, almost all animal species were represented but no single porcine species was recorded. This could be attributed to the Muslim dominance of Birnin Kebbi whose religion forbids the consumption of pork hence the low level of rearing of such specie and the 
complete absence of clinical cases associated with porcine in the record of the hospital during the study period. Majority of the clinical cases reported were in the ovine specie followed by caprine, avian, equine and bovine. This is in line with the observation of Ebbo et al. (2003) and Salihu et al. (2005) in Sokoto and Okolocha et al. (2007) in Kaduna. The most probable reason could be that more people in the study area keep ovine because it attract higher sale during 'Sallah' season.

The low number of bovine and equine species in this report may be due to absence of ambulatory record in this report owing to the larger size of these species which make them difficult to be moved to the clinic. In fact, equine which could easily be trotted to the clinic is a bit higher than the bovine in this report. Our view is contrary to the view of Salihu et al. (2005) who attributed such low presentation of bovine cases in their studies to the nomadic nature of rearing cattle. Our argument was based on the fact that there are many sedentary cattle farmers in Birnin Kebbi yet we have low presentation of bovine in this study. Canine and feline species though, are kept for security, hunting and as pets, their number in this report is low. This could be due to the partial prohibition of the keeping of such animals (especially dog) by Islam as well the fear of rabies (Garba et al., 2007).

Of the forty nine animal and poultry diseases diagnosed during the review period, helminthoses, fowl pox, lousiness, enteritis, were the most prevalent. This is in concordance with the report of some workers in other part of the country (Fatihu et al., 1999, 2002; Ebbo et al., 2003; Salihu et al., 2005; Okolocha et al., 2007). The high prevalence of helminthoses, enteritis, lousiness may not be unconnected with the low level of routine deworming and ectoparasite control (the level of which is only $19.5 \%$ in this report) as well poor housing and feeding management employed by some livestock farmers in Birnin Kebbi. This can further, be elucidated from the monthly pattern of disease distribution. It should be noted that the month of March (which is the late dry season when food and housing is scarce) recorded the highest number of all cases. On the other hand, the month of October (the beginning of early dry season when animals are just coming out of late rainy season where they were well fed and sheltered) recorded the least of all cases (Table I). This is a pointer that if the government and livestock owners can routinely deworm, feed and provide housing to livestock, an improved and high quality and quantity of livestock production will likely be attained.

In the avian specie, while Salmonellosis was the most prevailing poultry disease in Adamawa State (Garba et al., 2009) and Newcastle disease in Edo state (Olabode et al., 2008), in Birnin Kebbi, the most prevailing poultry disease was fowl pox and indeed the second most prevailing animal disease in this report. Majority of the poultry farmers in Birnin Kebbi abstained from injectable poultry vaccination including fowl pox due to cost of Veterinary labour. Pox virus survived long in the environment and can be disseminated by wind or even mosquitoes to a very long distance (Stephanine, 2002). This may be a reason why the occurrence of fowl pox was highest in the month of March 42 (65\%) (Table I). The prevalence of other moderately, less and least occurring disorders in the state which were reported by other workers (Cadmus et al., 1999; Fatihu et al., 2002; Ebbo et al., 2003; Salihu et al., 2005, Paul-Abiade et al., 2006; Olabode et al., 2008 and Garba et al., 2009) from other parts of the country; is a pointer to the government at all levels for the need to intensify surveillance and diagnostic machineries for prompt tracking of any animal disease in the country.

It was noted that more females $(54.3 \%)$ were accord better veterinary attention than male animals due to their productive abilities. The average monthly occurrence of cases was 66.2 cases. This is rather too low considering the preeminent role of livestock resources of the state. Furthermore, this is a pointer to the government of the need to educate and sensitize the general public on the relevance to be patronizing the only animal hospital in the state capital.

In conclusion, it is obvious that the entire list A to E reportable animal diseases in Nigeria were represented in this report. It is our opinion that the relevant government agencies would find this report useful in formulating policies that will prevent or minimize the occurrence of animal diseases. Especially, policies directed towards public awareness, provision of drugs for routine 
treatment, provision of subsidized supplementary livestock feeds and watering points amongst other things.

\section{ACKNOWLEDGEMENT}

We are grateful to the Director of Veterinary Services Kebbi State Dr. S.D. Bello, his deputy Dr. Bala Kakale and the entire staff of Birnin Kebbi Animal Hospital especially Dr. Dominic, Dr. Sanchi and Mal. Hussaini for their kind support and co-operation before and during the course of this investigation.

\section{REFERENCES}

ABDULKADIR, A.I. (1989): Infectious Diseases of Livestock in Nigeria. Ahmadu Bello University Press, Zaria-Nigeria. 5-7

ANYAM, A.A. (2006): A review of estrus synchronization technology in cattle. Nig. Vet Journal. 27(3): 63-72

CADMUS S.I.B., ABATAN, A.A. and MWANLE, P.G. (1999): Clinical cases in a private veterinary clinic in the federal capital territory, Abuja. Proceedings of the $36^{\text {th }}$ Annual congress of the Nigerian Veterinary Medical Association Held at Arewa house, Kaduna $25^{\text {th }}-29^{\text {th }}$ October, 1999. 85-88

EBBO, A.A., AGAIE, M.B., ADAMU, U., DENEJI, A.I. and GARBA, H.S. (2003): Retrospective analysis of cases presented to the veterinary teaching hospital, Usmanu Danfodiyo University, Sokoto(1993-2002). Nig. Vet. Journal. 24(3): 133-136

FATIHU, M.Y., IBRAHIM, N.D.G., OLADELE, S.B., MOHAMMED, B. and DIAFARA, A. (1999): Mortality observed in goats in Zaria, Nigeria. Proceedings of the $36^{\text {th }}$ Annual Congress of the Nigerian Veterinary Association. Held at Arewa house Kaduna, $25^{\text {th }}$ October, 1999. 120-124

FATIHU, M.Y., IBRAHIM, N.D.G., OLADELE, S.B., MOHAMMED, B. and DIAFARA, A. (2002): Recorded mortality in sheep in Zaria, Nigeria. Proceedings of the $39^{\text {th }}$ Annual Congress of the Nigerian Veterinary Association. Held at UDU-Sokoto, October, 2002. 176-181

GARBA, A., OBOEGBULEM, S.I; JUNAIDU, A.U; LOMBIN, L.H; MAKINDE, A.A; ELSA, A.T AND
OGUNSAN, A.E (2007): Dog the principal reservoir host for rabies in Nigeria: current report. Book of Proceedings of the Nig.Vet. Med. Association, $44^{\text {th }}$ Annual Congress- Delta '2007; An addendum from $43^{\text {rd }}$ NVMA Annual Congress Minna '2006:355-357.

GARBA, A., BOLAJOKO, B.M., BARDE, I.J., AHMED, A., SA'ADATU,I., AGANG, I., ABDULLAHI, A.S., BAKARI, H.A., TURAKI, U.A., ABDURRAHMAN, A and GOJI, N.O. (2009): Salmonellosis: a threat to commercial poultry production in Adamawa StateNigeria. Book of Abstrcats of the $46^{\text {th }}$ Annual Congress of the Nigerian Veterinary Medical Association. Held at Anambra $19^{\text {th }}-23^{\text {rd }}$ October, 2009. 71

OKOLOCHA, E.C., UMOH, J.U., NWANTA, J.N., SABO, G. and PALA, Y.Y. (2007): A survey of some important diseases of domestic animals diagnosed in Kaduna State, Nigeria. Proceedings of $44^{\text {th }}$ Annual Congress of the Nigerian Veterinary Medical Association Held at Delta, 2007. 217-222

OLABODE, H.O.K., EGHAFONA, N.O. and IYOHA, H. (2008). A retrospective (2004-2006): study of poultry diseases diagnosed at Benin, Edo State. Nig. Vet. Journal. 29(1):76-80

OLUKOLE, S.G. (2008): Assessment of enforcement and impacts of two veterinary legislations in Oyo State, Nigeria. Nig. Vet. Journal.29(3): 41-47

PAUL-ABIADE, C.U., ONUNKWO, J.I. and AKA, L.O. (2006): A questionnaire survey of reports of livestock disease outbreak in Enugu North, South east, Nigeria. Nig. Vet. Journal 27(3): 1-5

RIM (1992): National Livestock Resources. Federal Department of Livestock and Pest Control Services, Abuja in collaboration with Resource Inventory and Monitoring, United Kingdom

SALIHU, M.D., ABUBAKAR, M.S., UMAR, A. and YAHAYA, H.S. (2005): A retrospective (2000-2004) study of diseases of livestock at Sokoto, Nigeria. Proceedings of the $42^{\text {nd }}$ Annual Congress of the Nigerian Veterinary Medical Association held at Maiduguri, 2005.33-35

STEPHANINE, S (2002): Avian pox: a curse for afflicted birds. DVRC Journal, http://www.dvrconline.org/avianpox.html. Downloaded on 25th September, 2010. 